\title{
Effects of Guidance and Counselling Services on Students' Interpersonal, Study, Vocational and Problem-Solving Skills in Selected Public Universities in Zambia
}

\author{
Abigail Mukuwa Tuchili \\ University of Zambia, School of Education \\ P.O. Box 32379, Lusaka. Zambia \\ Dr. Daniel Ndhlovu \\ University of Zambia, Institute of Distance Education \\ P.O. Box 32379, Lusaka. Zambia
}

\begin{abstract}
This paper is an extract from an on-going PhD study. The paper is guided by the objective which sought to investigate whether students who received guidance and counselling services perform better than their counterparts who did not in regard to development of interpersonal, study, vocational and problem-solving skills. In order to establish relationship between the two groups of students, a correlational design was used, with a sample of 105. In-depth interview guides, focus group discussions and self-administered questionnaires were used to collect data. Thematic analysis and SPSS were used to analyse the data. The study found that there was statistically significant difference between students who received guidance and counselling services and those who did not. In conclusion, the paper argues that students who received guidance and counselling services were better developed in interpersonal, study, vocational and problem-solving skills than their counterparts in the control group. On the basis of these findings, the study recommends that there is need to encourage all students in public universities to access guidance and counselling for them to develop interpersonal, study, vocational and problem-solving skills.
\end{abstract}

Keywords: Effects, Guidance and counselling services, interpersonal, study, vocational, problem-solving.

\section{INTRODUCTION}

\subsection{Background to the Study}

The education system in Zambia has faced dynamic and rapid changes that have had overwhelming effects on the learner, learning institutions and society at large. Since independence in 1964, there have been numerous changes in policy formulation and directives, one of these being the introduction of guidance and counselling services provision at all levels of the education system. The policies on guidance and counselling have been aimed at preparing young people to face challenges they may encounter in and out of the education system. The function of education is to provide opportunities for each student to reach his or her full potential in the areas of educational, vocational, social-personal, and emotional development (Kauchak, 2011). In order for students to realise this function, the tertiary institutions are expected to provide guidance and counselling services (GCS) as an integral part of their education. When guidance and counselling services are provided they help prepare students to assume increasing responsibility for their decisions and grow in their ability to understand and accept the results of their choices (Kauchak, 2011). The ability to make such intelligent choices is not innate but, like other abilities, must be developed. However, some students' performance in regard to interpersonal, study, vocational and problem-solving skills need to be up scaled. Some of the behaviour exhibited by some students in some public universities leaves much to be desired. It is occasionally characterised by poor performance, truancy from classes, riots, demonstrations, drinking and all sorts of vices. Hence, there was need to compare whether students who access guidance and counselling services in Zambia's public universities perform better than their counter parts who may not access the services.

Effects of guidance and counselling services on students' development of interpersonal, study, vocational and problem-solving skills in Zambia's public universities motivated this study. In this 
study the terms Guidance and Counselling are used independently to mean different things. Guidance is defined as giving direction to an individual student so that he or she grows into a responsible person leading a fulfilling life. As Lindhard (1985) and Gibson and Mitchell (2007) state, guidance is an activity in which the teacher brings students into contact with the world as it really is and helps them to make choices wisely in their day to day lives. It may be said that guidance is forward looking and thus preventive. Counselling, on the other hand, is curative in that it aims to help an individual to accept a problematic situation which he or she is faced with, by way of helping him or her to make an informed decision from any available choices. In a nutshell, while guidance is given before one faces a problem, counselling is given to a person already facing a problem. In this study, this is the way these two terms are used.

\subsection{Statement of the Problem}

Although guidance and counselling is offered to students in education institutions in Zambia, its effect on shaping behaviour among university students is not known. The purpose of the study therefore, was to establish whether students who access guidance and counselling services perform better in regard to development of interpersonal, study, vocational and problem-solving skills than their counterparts who do not access this service.

\subsection{Objective of the Study}

To establish whether students who access guidance and counselling services perform better in regard to development of interpersonal, study, vocational and problem-solving skills than their counterparts who do not access this service.

\subsection{Research Question}

Specifically, the study addressed the following research question: 'Do students who receive guidance and counselling services perform better in interpersonal, study, vocational and problem-solving skills than their counterparts who do not access the services?

\subsection{Significance of the Study}

At the time when it is not known whether guidance and counselling has an effect on students' development of interpersonal, study, vocational and problem-solving skills; a study of this nature was significant to fill this gap.

\subsection{Study Site}

The study sites for this study were: University of Zambia, Copper Belt University and Kwame Nkrumah University.

\subsection{Limitations}

It was problematic to collect information from some target groups who did not feel comfortable to talk about their interpersonal skills thus cautiousness must be exercised when generalising the results of the study. Nonetheless, the researcher relied on triangulation to validate data

\section{Methodology}

This study used a correlational study design. Correlation means association - more precisely it is a measure of the extent to which two variables are related, (McLeod, 2008). A correlation identifies variables and looks for a relationship between them (Cresswell, 2007). Quantitative research designs are either descriptive (subjects usually measured once) or experimental (subjects measured before and after a treatment). A descriptive study establishes only associations between variables (Teddlie \& Tashakkori, 2009). This study sought to do establish the association between variables.

The study population comprised second and third year students in three selected public universities in Zambia. This type of population was chosen because it met the unique characteristics of participants with knowledge about guidance and counselling services offered in the universities.

The sample comprised three (3) Deans of Students' Affairs (DOSA), 12 Counsellors, and 90 students. The total number of respondents was 105. The benchmark for inclusion of this sample was that these Deans are responsible for the students' affairs, while the counsellors are equally responsible for the students' needs by providing the guidance and counselling services to all students. The students had lived experiences of using the guidance and counselling services and would provide required data. 
Purposive and simple random sampling procedures were used to select the sample from both the students' body and university officials. Kombo and Tromp (2006) state that the power of purposive sampling procedure lies in selecting information with rich cases for in-depth analysis related to the central issue understudy. In view of this, purposive sampling was chosen for the study because the research required a sample that would provide rich information on the role of guidance and counselling to shape student's behaviours.

Questionnaires, focus group discussion and interview guides were used to collect data. These three sets of tools provided an opportunity for triangulating the findings, an approach which increases credibility in the findings (Patton, 2002). As such, the study findings from these three tools are presented concurrently.

Qualitative data collected were analysed using thematic analysis, while the quantitative data from questionnaires was analysed using Pearson's Chi-square, SPSS and excel to create pie charts and tables.

\section{FINDINGS AND DISCUSSION}

\subsection{Development of Interpersonal and Study Skills}

The t-test results in Table 1below indicate that there was statistically significant difference between students who received guidance and counselling services and those who did not in regard to development of interpersonal and study skills. The findings indicate that the calculated $p$ value is less than 0.05 . The implication is that guidance and counselling services provided in public universities enhances the development of students' interpersonal and study skills to a greater extent as compared to the students in public universities who do not utilise the services. Students who received interpersonal and study skills counselling services performed better than those who did not receive. According to a Chi-Square test conducted at 5\% level of significance and P-Value obtained at 5\% level of significance is 0.003 is less than 0.05 , then we accept that, students who received interpersonal and study skills performed better than those who did not receive guidance and counselling.

Likelihood ratios tell us how much we should shift our suspicion for a particular test result, in this case the Chi-Square test (0.003). The fact that tests can be positive or negative; there are at least two likelihood ratios for each test. The "positive likelihood ratio" (LR+) tells us how much to increase the probability of development of interpersonal and study skills if the test is positive, while the "negative likelihood ratio" (LR-) tells us how much to decrease it if the test is negative.

Similarly, results from the in-depth interviews with Deans of Student Affairs (DOSAs) indicate that students who access the services do indeed perform better as confirmed by one Dean who said: 'After receiving counselling, some students have confessed to have become more positive about life, confident and record improved results'. This finding is in line with previous findings by Nyaga (2011) whose study in Kenya revealed that guidance and counselling provision had an effect on performance of students who received the service.

\section{Students' responses through a Pearson Chi-square test using SPSS formula}

Table1. Students' development of interpersonal and study skills

\begin{tabular}{|l|l|l|l|}
\hline Chi-Square Test & Value & df & P-Values \\
\hline Pearson Chi-Square & $9.029^{\mathrm{a}}$ & 1 & .003 \\
\hline Likelihood Ratio & 9.212 & 1 & .002 \\
\hline N of Valid Cases & 90 & & \\
\hline
\end{tabular}

$\mathrm{X}^{2}=9.029$

$\mathrm{df}=1$

P-Value $=0.05$

The results in the figure below indicate that $51.1 \%$ of the student respondents had received study skills through guidance and counselling while $48.9 \%$ did not receive this service. Further these stated that the services enhanced their performance. This could mean that those that had accessed the service 
do perform better in regard to study skills. During a Focus Group Discussion (FGD), one student said: 'Guidance and counselling helps especially when making decisions with study skills and change of courses. Those who do not receive guidance wish they had sought the service when they are in trouble'.

Enhancement of skills is supported by one counsellor who said: 'Guidance and counselling indeed shapes behaviour of students. We see a change in some of the decisions they make. In this sense it does help shape behaviour to improve on study skills and academic life in general'. 'There is a general growth in academic and social growth'. Students are provided with self-direction'. 'Further, GCS helps in understanding one's strengths, limitations and how to solve problems'.

This is agreed by Chireshe, (2006), who indicates that access to guidance and counselling provision helps students to enhance their performance. The researcher also found out that most students revealed that their performance improved due to access of the guidance and counselling services. The researcher is of the view that guidance and counselling provision has a positive effect on how to nurture students who have varying abilities, capacities, interests and unlimited potential; and to prepare these individuals to become effective functioning members of their changing societies.

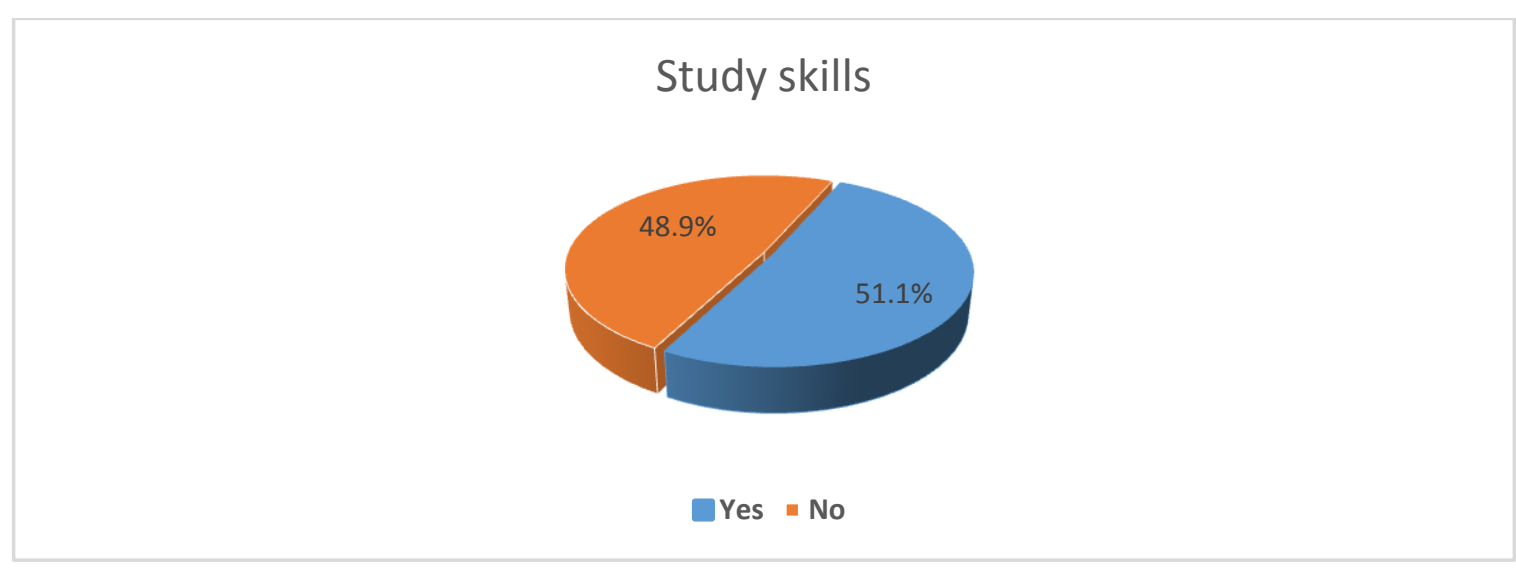

Figure1. Students' development of study skills

\subsection{Development of Vocational and Problem Solving Skills}

Another Chi-Square test was conducted at 5\% level of significance where P-Value is .05. The ChiSquare Test P-Values obtained was .000 which is less than the P-Value at 5\% (.05) level of significance. Therefore, according to the test, it is worth to believe that, students who received guidance and counselling in regard to Vocational and Problem-solving skills tended to perform better academically than their counterparts. It can also be said that, at this level there was $95 \%$ confidence to believe that students who received guidance and counselling performed better academically than their counterparts.

Table2. Vocational and Problem solving skills

\begin{tabular}{|c|c|c|c|}
\hline \multicolumn{4}{|l|}{ Chi-Square Test } \\
\hline & Value & $\mathrm{df}$ & P-Value \\
\hline Pearson Chi-Square & $48.940^{\mathrm{a}}$ & 1 & .000 \\
\hline Continuity Correction $^{b}$ & 45.279 & 1 & .000 \\
\hline Likelihood Ratio & 55.023 & 1 & .000 \\
\hline $\mathrm{N}$ of Valid Cases & 90 & & \\
\hline
\end{tabular}

$\mathrm{X}^{2}=48.940$

df $=1$

P-Value $=0.05$

It was clear from this finding that students who access guidance and counselling services perform better as stated by (100\%) of the DOSAs during the interviews. This is also confirmed by counsellors who said: 'Students' behaviour improves in regard to academic growth and social adjustment, so guidance and counselling is relevant in shaping students' behaviour'; 'It provides self-direction and optimum individual development; 'It helps in understanding one's strengths, limitations and how to solve problems'. This is in line with Nyaga (2011) who found that guidance and counselling had an 
impact in resolving student's social problems and discipline issues. The researcher is of the view that guidance and counselling provision assists students to perform better than they would if they did not access the services.

The figure below reveals that $65.5 \%$ confirmed to have received problem-solving skills while $34.4 \%$ stated that they had not. The above comparisons indicate that those that access the services could be performing better in the listed skills. The researcher is thus of the view that guidance and counselling services have a critical role to play in assisting students to improve the vocational and problemsolving skills.

\section{Problem solving}

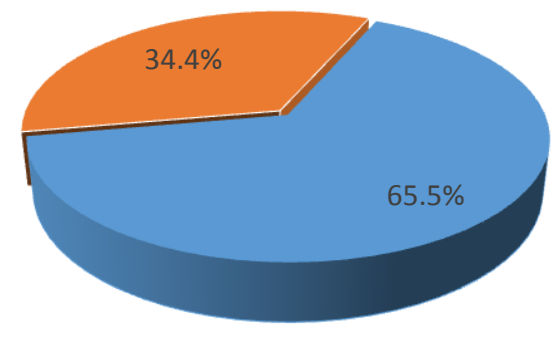

Yes $=$ No

Figure2. Showing performance in problem-solving skills

Below is a brief summary of the findings:

- The results of the study revealed that students who receive guidance and counselling services perform better in interpersonal, study skills, findings indicate that the calculated $p$ value is less than 0.05. Chi-Square test conducted at 5\% level of significance and P-Value obtained at 5\% level of significance is 0.003 is less than 0.05 , then we accept that, students who received interpersonal and study skills counselling the above tended to perform better than those who did not receive guidance and counselling.

- Another Chi-Square test on vocational and problem solving skills was conducted at $5 \%$ level of significance where P-Value is .05. The Chi-Square Test P-Values obtained was .000 which is less than the P-Value at 5\% (.05) level of significance.

- The study further revealed that guidance and counselling can enhance students' interpersonal, study, vocational and problem solving skills.

The results indicate that students receive guidance and counselling services in the components listed above performed better than their counterparts who did not. The results revealed that the source of positive behaviour can be associated to the use of the guidance and counselling services.

\subsection{Summary of Guidance and Counselling Services}

The table below shows a summary of a cross tabulation of SPSS of number students who indicated that they had used components of the guidance and counselling services. The results indicated that the majority of the students that used guidance and counselling services showed positive change for instance personal, vocational, problem solving and study skills had improved. Similarly, this is the same for all the other components of the guidance and counselling services offered in the sampled universities.

The students stated categorically that guidance and counselling helps to enhance positive behaviour in regard to interpersonal skills. On the same question of whether guidance indeed does have an effect on students' interpersonal, study, vocational, and problem solving skills, the counsellors who responded to the questionnaire indicated as below:

'GCS encourages positive acceptable behaviour among students and helps to cognitively reconstruct their thinking'. 'The various skills students receive through guidance and counselling helps change them for the better and is very relevant to students' wellbeing'. 
The above findings from deans, counsellors and students seem to suggest that guidance and counselling services do have a positive effect on behaviour of students in public universities in Zambia.

Table3. Utilisation in relation to Behavioural change and enhanced skills

\begin{tabular}{|c|c|c|c|c|}
\hline & \multicolumn{2}{|c|}{$\begin{array}{c}\text { Cross tabulation for service utilisation } \\
\text { verses behavioural change }\end{array}$} & \multirow[t]{2}{*}{ Total } \\
\hline & & yes & no & \\
\hline \multirow[t]{2}{*}{ Personal } & yes & 44 & 13 & 57 \\
\hline & no & 24 & 9 & 33 \\
\hline \multicolumn{2}{|l|}{ Total } & 68 & 22 & 90 \\
\hline \multirow[t]{2}{*}{ Vocational } & yes & 57 & 13 & 70 \\
\hline & no & 11 & 9 & 20 \\
\hline \multicolumn{2}{|l|}{ Total } & 68 & 22 & 90 \\
\hline \multirow[t]{2}{*}{ Study skills } & yes & 36 & 11 & 46 \\
\hline & no & 35 & 11 & 44 \\
\hline \multicolumn{2}{|l|}{ Total } & 68 & 22 & 90 \\
\hline \multirow[t]{2}{*}{ Problem solving skills } & yes & 46 & 13 & 59 \\
\hline & no & 22 & 9 & 31 \\
\hline \multicolumn{2}{|l|}{ Total } & 68 & 22 & 90 \\
\hline
\end{tabular}

\section{CONCLUSION AND RECOMMENDATIONS}

\subsection{Conclusion}

Based on the study findings, it can be concluded that guidance and counselling services can enhance development of students' interpersonal, study, vocational and problem-solving skills in public universities in Zambia. Students, counsellors and DOSAs all acknowledge that guidance and counselling can be used to enhance positive behaviour in students and consequently shape the behaviour positively. It may also be concluded that if all students accessed guidance and counselling services, they would be a general improvement in their performance; and how they would handle the social and academic challenges they may encounter through the choices they make and also the demands of everyday life.

\subsection{Recommendations}

Based on the perceived benefits of guidance and counselling as a tool of enhancing students' interpersonal, study, vocational and problem solving skills shaping students' behaviour, it is recommended that:

- A mandatory policy should be put in place to offer GSC to all students. This will ensure that all students benefit from the guidance and counselling services.

- Encourage all students in public universities to access guidance and counselling services to enhance holistic their development. This is because there is evidence that this has a positive effect on the development of vocational, interpersonal, study and problem solving skills.

- There should be adequate provision of materials and infrastructure (counselling rooms) in all learning institutions and equipping course lecturers with counselling skills.

- Universities must increase number of counsellors in all public universities. This is because the study found out that all the public universities have less the number of required counsellors to attend to students' needs.

\section{REFERENCES}

Abid, H. (2006). Effect of guidance services on study attitudes, study habits and academic achievement of secondary school students. Bulletin of Education \& Research, 28(1), 35-45.

Chireshe, R. (2006). An Assessment of the effectiveness of school Guidance and Counselling Services in Zimbabwean secondary Schools. Doctoral Dissertation: University of South Africa.

Creswell, J. W. (2003). Research design: Qualitative, quantitative, and mixed methods approaches (2nd ed.). Thousand Oaks, CA: Sage.

Cresswell, J. W., \& V. L. Plano Clark. (2007). Designing and Conducting Mixed Methods Research. Thousand Oaks, CA: Sage Publications. 
Effects of Guidance and Counselling Services on Students' Interpersonal, Study, Vocational and Problem-Solving Skills in Selected Public Universities in Zambia

Gibson, R. L. and Mitchell, M. H. (2007).Introduction to Guidance and Counselling. $7^{\text {th }}$ ed. New York: Macmillan

Kathuri, J.N., \& Pals, D.A.(1993). Introduction to Educational Research. Njoro: Egerton University Press.

Kauchak. D. P. (2011). Introduction to teaching: Becoming a professional. Upper Saddle River, NJ: Prentice Hall.

Kombo, K. D. and Tromp, L. A. (2006). Proposal and Thesis Writing: An Introduction Nairobi: Pauline Publications Africa.

Lindhard, N. (1985). Guidance in the Classroom, $3^{\text {rd }}$ ed. Cape Town: Maskew Miller Pty Ltd

McLeod, S.A. (2008). Correlation Retrieved from www.simplypsychology.org/correlation.html

Ministry of Education (1996). Educating Our Future: National Policy on Education, Lusaka: ZEPH.

Ndhlovu, D. (2015). Theory and Practice of Guidance and Counselling for Schools and Colleges. Lusaka: University of Zambia Press.

Nyaga, K. V. (2011). Effectiveness of Guidance and Counselling Services and Development of Students' Academic, Social and Personal Competencies in Public and Private Universities in Kenya: Doctoral Dissertation, Meru Chuka University College.

Patton (2002), Patton, M. Q. (2002). Qualitative evaluation and research methods (3rd ed.).

Thousand Oaks, CA: Sage Publications, Inc.

Rohlf F. James and Robert R. Sokal (1994) Statistical Tables, 3e,: W.H. Freeman and Company.

Teddlie, C. \& A. Tashakkori (2009). Foundations of Mixed Methods Research. Thousand

Oaks, CA: Sage Publications. Tashakkori, A., \&Teddlie, C. (2003b). The past and future of mixed methods research: From data triangulation to mixed model designs. In Tashakkori, A., \& C. Teddlie (Eds.), Handbook of Mixed Methods in Social and Behavioral Research. Thousand Oaks, CA: Sage Publications.

Tuchili, A. M. (2008). Evaluation of school guidance and counselling services provision in selected schools in Lusaka District. Unpublished MA.Thesis. UNZA: Lusaka.

\section{AUTHORS' BIOGRAPHY}

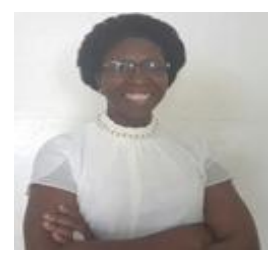

Abigail Tuchili, is an Educational Psychologist and a $\mathrm{PhD}$ candidate in the School of Education, Department of Educational Psychology, Sociology and Special Education (EPSSE) at the University of Zambia. She is currently serving as Senior Curriculum Specialist at the Curriculum Development Centre (CDC) in the Ministry of General Education (MOGE) - Zambia. She has over 10 years' experience in the field of curriculum design and development and over 13 years' as a teacher. Her PhD thesis is about 'How guidance and counselling can shape students' behaviour in selected public universities in Zambia'. Abigail has participated in various National and International fora on guidance and counselling. She is currently a member of the Psychology Association of Zambia (PAZ) and National Counselling and Guidance Association of Zambia (NACGAZ); and part time lecturer of Educational Psychology at the University of Lusaka.

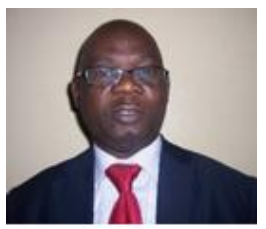

Dr. Daniel Ndhlovu, is a Senior lecturer in the Department of Educational Psychology, Sociology and Special Education at the University of Zambia. He holds a doctoral degree in Special Education, Master's degree in Education and Bachelor's degree in Special Education from the University of Zambia. In addition to lecturing, he has held senior administrative positions at the University of Zambia which includes Assistant Dean Postgraduate in the School of Education and Assistant Director Postgraduate in the Institute of Distance Education. He has over 29 years teaching and lecturing experience at secondary school and tertiary levels of education. He has done numerous research activities and publications in local and international refereed journals. His latest publication is Teaching materials in phonology for pupils with hard of hearing in selected schools of Chongwe District, Lusaka province, Zambia authored by Rose Chikopela and Daniel Ndhlovu. International Journal of Multidisciplinary Research and Development Online ISSN: 2349-4182. 